Ann Thorac Surg. 2011 February ; 91(2): 499-505. doi:10.1016/j.athoracsur.2010.10.059.

\title{
Outcomes and Cost of Cardiac Surgery in Octogenarians is Related to Type of Operation: A Multi-Institutional Analysis
}

\author{
Castigliano M. Bhamidipati, DO ${ }^{*}$, Damien J. LaPar, MD*, Edwin Fonner Jr., DrPH ${ }^{\dagger}$, John A. \\ Kern, MD, FACS, Irving L. Kron, MD, FACS, and Gorav Ailawadi, MD, FACS \\ Division of Thoracic and Cardiovascular Surgery, Department of Surgery, University of Virginia \\ School of Medicine, Charlottesville, VA
}

\section{Abstract}

Background-Given recent economic implications in caring for an aging population, we sought to determine if postoperative complications and costs for octogenarians differed based on the type of cardiac operation.

\begin{abstract}
Methods-From 2003 to 2008 patients who underwent cardiac operations at 16 different centers were identified from the Virginia Cardiac Surgery Quality Initiative and selected into two cohorts ( $<80$ years and $\geq 80$ years). Octogenarians ( $\geq 80$ years) were stratified into isolated primary coronary bypass graft, aortic valve, mitral valve, or combined operation. Preoperative risks, outcomes, and costs were analyzed. Case-mix adjusted models for mortality and major complication rate were developed.
\end{abstract}

Results-We examined 45,731 patients, of which 3,079 were octogenarians $(82.7 \pm 2.5$ years). Compared to younger patients, octogenarians incurred higher mortality ( $6.5 \%$ vs. $3.1 \%, P<0.001)$ and major complication rates $(13.2 \%$ vs. $8.4 \%, P<0.001)$ with only incrementally higher total costs $(P<0.001)$. Among octogenarians mortality was similar despite the operation. Cross clamp and cardiopulmonary bypass time $(P<0.001)$, hospital length of stay $(P=0.001)$, and major complication rate $(P=0.002)$ were highest for combined operation. Despite the fewest complications, mitral valve operation had the highest total costs $(P<0.001)$. Type of operation was not predictive of mortality or major complication rate. However, age, female gender, emergent status, and prolonged cardiopulmonary bypass time, were independently associated with death despite risk-adjustment.

Conclusions-Advanced age confers increased risks and incrementally higher costs in patients undergoing cardiac operations. Isolated mitral and combined procedures have the highest complications and costs. Any proposed cardiac operation in octogenarians mandates careful consideration of resource utilization.

\section{Keywords}

Health economics; Outcomes

Corresponding Author: Gorav Ailawadi, MD, Division of Thoracic \& Cardiovascular Surgery, University of Virginia Health System, P.O. Box 800679, Charlottesville, VA 22908, Office: 434-924-9314, Fax: 434-982-3885, gorav@ virginia.edu.

These authors are equal contributors.

$\dagger$ Virginia Cardiac Surgery Quality Initiative, Richmond, VA

Presented at the $59^{\text {th }}$ Annual Scientific Sessions of American College of Cardiology 2010 Atlanta, GA

Publisher's Disclaimer: This is a PDF file of an unedited manuscript that has been accepted for publication. As a service to our customers we are providing this early version of the manuscript. The manuscript will undergo copyediting, typesetting, and review of the resulting proof before it is published in its final citable form. Please note that during the production process errors may be discovered which could affect the content, and all legal disclaimers that apply to the journal pertain. 


\section{Introduction}

Elderly Americans are the fastest growing fraction of our population, and are expected to double by $2050 .{ }^{1}$ The United States healthcare system will care for an estimated 32.9 million octogenarians ( $\geq 80$ years) by 2050 , up from 11.5 million today. ${ }^{1}$ Therefore, understanding the cost and outcomes of cardiovascular procedures in octogenarians is an important consideration and has significant implications for the evolving healthcare sector.

Octogenarians comprise a unique subset of patients with typically higher risk profiles and expectant perioperative complications. However, a recent prospective analysis evaluating a quality of life index in octogenarians found that $>90 \%$ of patients participated in social, cognitive and physical programs up to 5 years following cardiac surgery, suggesting that surviving octogenarians remain at home, function independently, and engage in regular leisure activities. ${ }^{2}$ Several groups have concluded that cardiac operations in octogenarians have improved quality of life despite increased hospital mortality, postoperative stroke, and longer hospital stay. ${ }^{3-6}$

Cardiac surgeons are increasingly treating octogenarians as part of their practice. As such, performing cardiac operations in this patient population requires an understanding of both, the expectant outcomes and costs incurred during treatment. Unlike other subspecialties, ${ }^{7}$ there is limited data on postoperative outcomes and total costs among octogenarians undergoing major cardiac operations, and evaluating them using a statewide registry is the purpose of our work.

\section{Patients and Methods}

\section{Registry Source}

Multi institutional de-identified data from 2003 through 2008 was obtained through the Virginia Cardiac Surgery Quality Initiative (VCSQI). The VCSQI is a voluntary consortium of hospitals and cardiac surgical practices providing open-heart surgery in the Commonwealth of Virginia. Greater than $99 \%$ of procedures were performed by member institutions and VCSQI collects cardiac surgical data from all patients undergoing surgery at these centers, according to the definitions established by the Society of Thoracic Surgeons (STS). Analysis of this registry for quality review and outcomes was not considered human subjects research, and was exempted by the University of Virginia's Human Investigation Committee. Participating institutions were also exempted given the Health Insurance Portability and Accountability Act regulations, due to consideration extended through the Small Business Agreement for Business Associates between each hospital, their surgical providers, and the VCSQI.

\section{Study Population}

De-identified patient data was separated into two cohorts and compared based on age, $<80$ years and $\geq 80$ years of age. Subsequently, all octogenarians who underwent primary operations (reoperations not excluded) were stratified into 4 groups: isolated coronary artery bypass graft (CABG), isolated aortic valve (AV), isolated mitral valve (MV), and mitral/ aortic valve procedure plus coronary revascularization $(\mathrm{V}+\mathrm{CABG})$. Patients were stratified by procedure as coded in the VCSQI to avoid erroneous inference, for example octogenarians who underwent "other procedures" were excluded for analysis, as the administrative dataset does not clarify the operation. Missing data completely at random underwent case-wise deletion to ensure $<10 \%$ missing values prior to analysis. 


\section{Statistical Analysis}

Primary outcomes evaluated included operative mortality, major complication rate, and total costs. A major complication was defined to include permanent stroke, renal failure as defined by the STS, prolonged ventilation ( $>24$ hours), deep sternal wound infection, or reoperation for any reason.

The statistical significance of differences in proportions for categorical variables was evaluated by the Pearson $\chi^{2}$ or Fisher's exact test where appropriate $(P<0.05)$. The statistical significance of differences in mean values for continuous variables was assessed by single factor analysis of variance $(P<0.05)$. Results for the total series of hypothesis tests conducted were corrected for multiple comparison bias by adjusting each probability by the false discovery rate. Data are shown as number $(\mathrm{N})$ with percentage by group $(\%)$, or mean with standard deviation (SD), except where indicated otherwise.

Separate multivariable regression models for mortality and major complication rate were developed to calculate the adjusted odds of an adverse outcome, by controlling for differences in patient demographics, preoperative characteristics, and operative variables. Covariate selections as shown in Tables 1 and 2 were made apriori, irrespective of univariate analysis significance, based upon established literature. The models' predictive capacity to discriminate was measured using the area under the receiver operator characteristic curve (AUC). The Hosmer-Lemeshow $\chi^{2}$ test for goodness-of-fit was performed to assess differences in model calibration for deciles of model probabilities. Adjusted odds ratios are presented for each covariate along with their $95 \%$ confidence interval (CI). All data were analyzed using the Statistical Package for Social Sciences ${ }^{\mathrm{TM}}$ (SPSS $\left.^{\mathrm{TM}}\right) 17$ (SPSS Inc., Chicago, IL).

\section{Results}

\section{Patient characteristics}

Using the VCSQI, we identified 45,731 patients who underwent a cardiac operation between 2003 and 2008. Patients were separated into two major cohorts, patients $<80$ years age $(91 \%)$ and $\geq 80$ years of age $(9 \%)$.

Mean age of an octogenarian who underwent a cardiac operation was $82.7 \pm 2.5$ years (Table 3 ). The incidence of peripheral vascular disease, cerebrovascular disease, stroke, and hypertension were higher in the octogenarian group, while there were more patients with diabetes, dyslipidemia, and endocarditis in the younger cohort ( $P<0.001$, respectively).

Octogenarians more frequently underwent valve or combined operations (Table 4), while younger patients more commonly underwent isolated coronary revascularization $(P<0.001$, respectively).

Postoperative mortality and major complications were higher in the octogenarians $(P<0.001$, respectively). Specifically, hospital readmission rate $(P=0.03)$, intensive care unit length of stay $(P<0.001)$, and most postoperative complications were higher among octogenarians (Table 5).

\section{Octogenarians stratified by type of operation}

Octogenarians were stratified by operation (Table 6): primary CABG $(\mathrm{N}=1,992), \mathrm{AV}$ $(\mathrm{N}=352)$, MV repair/replacement $(\mathrm{N}=81)$, or $\mathrm{V}+\mathrm{CABG}(\mathrm{N}=654)$. Those undergoing AV replacement tended to be older ( $83.2 \pm 2.9$ years) than patients undergoing other operations. AV operations were most often elective, compared to CABG, which were most frequently urgent or emergent $(P<0.001$, respectively). Left ventricular ejection fraction $(55.7 \pm 11.6 \%)$ 
was highest in patients undergoing MV $(P=0.001)$, despite being the least commonly performed procedure.

Cardiopulmonary bypass and aortic cross clamp times were lowest for CABG (Table 7). Importantly, postoperative sepsis, stroke, perioperative acute myocardial infarction, pneumonia, dialysis dependent renal failure, ICU length of stay, and all-cause mortality were similar despite type of operation. Reoperation and gastrointestinal bleed were highest after MV operation $(P<0.001$, respectively) while concomitant operations had the highest rates of renal failure, prolonged ventilation, major complications, and longest hospital LOS. Despite these differences, unadjusted total costs were highest after MV operation $(P<0.001)$.

\section{Adjusted mortality and major complication rate in octogenarians}

Multivariable regression models were developed for mortality (Table 1) and major complications (Table 2). Female gender, age, preoperative arrhythmia, non-elective operative status, cardiopulmonary bypass and aortic cross clamp times were independent predictors for both mortality and morbidity. Importantly, type of operation was not predictive of either adverse outcome.

\section{Comment}

Several studies have evaluated the significance of age on cardiac surgery outcomes. $3,4,8,9$ However, to the best of our knowledge, there has been no prior comprehensive attempt to review outcomes and costs stratified by different cardiac operations, especially among octogenarians. Additionally, findings of the current work represent all cardiac operations in octogenarians between 2003 and 2008 in Virginia, the $12^{\text {th }}$ most populous state. Taken together, as the population of octogenarians increases, ${ }^{5,6}$ our investigation of cardiac procedures performed in this cohort provides surgeons with case-mix adjusted outcomes for better surgical risk assessment.

The STS predicted risk of mortality (PROM) for cardiac procedures is an instructive tool, yet is not computable for all combinations of cardiovascular operations. Importantly, as the formula for PROM calculation changes, the year-to-year variation in predicted risk can be difficult to explain. Nevertheless, increasing age and adverse outcomes have been long known to have a linear relationship. Baskett and colleagues reviewed isolated CABG operations performed on octogenarians, and found higher rates of stroke and death compared to younger patients. ${ }^{10}$ Our findings support these results and those from other series, ${ }^{3,}, 9$, 11-14 which generally describe an expectantly worse prognosis in patients $\geq 80$ years of age. Younger patients in our series more commonly had undergone a previous valve procedure, compared to octogenarians more commonly having undergone previous isolated CABG, suggesting a shift in risk profiles and the disease burden in Virginia.

Sundt and colleagues evaluated outcomes in octogenarians after aortic valve surgery and reported an $11 \%$ mortality with a 6 day mean ICU stay, and 15 day mean hospital LOS. ${ }^{15}$ Despite higher mortality and longer ICU length of stay in octogenarians, hospital stay was similar (approximately 12 days) between the $<80$ and $\geq 80$ years groups, consistent with previous reports.

In our series, the unexplainable high reoperation rate due to bleeding and/or tamponade, and gastrointestinal event rate in octogenarians after isolated mitral surgery provide some explanation for the higher total costs $(\approx 2,500$ difference from the next closest group), yet raise important concerns regarding low volume outcome effects of this procedure.

Alternatively, preoperative NYHA Class IV and arrhythmias were also commonly seen in 
the isolated MV group in comparison, perhaps explaining the complication rate and mortality.

Postoperative myocardial infarction was an uncommon complication, while postoperative atrial fibrillation was the most common complication irrespective of type of operation. Major complication rate was highest in patients undergoing concomitant operations, and paralleled longer LOS. However, length of hospitalization did not equate to higher total costs, suggesting hidden or additive costs that must be considered when evaluating potential octogenarian cardiac surgery patients. For example, device related costs do not linearly influence hospital LOS. It is important to realize that institutionally reported costs to be included in administrative databases might not accurately differentiate indirect from direct costs and the reimbursement formula based on relative value units is also hard to clarify.

Our multivariable modeling spanned the vast majority of cases yielding an acceptable AUC considering very minimal missing data, for mortality and major complication rate. Despite robust models that controlled for various influences, no specific operation independently predicted adverse outcomes. We attribute our findings to improved surgeon proficiency with high critical care standards as similar findings are described in other series. $5,6,9,16,17$ Still of concern, however, female gender continues to remain a risk factor for cardiac operations. Albeit expectant, increasing age, presence of preoperative arrhythmia, and ejection fraction independently predicted mortality and major complications. Our finding of non-elective operative status increasing the odds of poor outcomes is not surprising, though no specific operation being more risky than the other after adjustment suggests that patient preoperative risk factors, rather than specific operation, is the more significant predictor of outcomes.

There are some notable limitations. The current review is a retrospective analysis with preset variables that limit prognostic potential. Secondly, there may be a selection and regional treatment bias as there likely exists patterned patient referral and procedural bias that varies across the state. Furthermore, as non-random missing data are not imputable, case-wise deletion could lend erroneous conclusions. The VCSQI reports short-term outcomes, and hence any long-term effects or quality of life measures cannot be evaluated. Hospital or surgeon volume can influence outcomes, and these important confounders are not reviewed by our analysis. Since the cost data is cumulative, hospital, procedure, device, and physician costs are not separable and when independently evaluated, could suggest different implications. Lastly, evolving trends and improvements in the management of octogenarians over the review period has influenced our findings. We attempted to minimize these differences, by developing logistic regression models using clinically relevant factors.

\section{Conclusions}

Advanced age ( $\geq 80$ years) confers increased but acceptable risks with common cardiac operations. Mortality is not dependent upon type of operation in this elderly cohort. Importantly, female gender, NYHA functional class IV heart failure, long cardiopulmonary bypass time, and non-elective operative status are independently predictive of major complications in octogenarians. Isolated mitral and concomitant operations have higher complications and higher total costs compared to isolated CABG or isolated aortic valve operations. Any proposed cardiac operation in an octogenarian mandates careful consideration of resource utilization and risk-to-benefit ratio.

\section{Acknowledgments}

Supported by T32/HL007849 (CMB, DJL) from the National Heart, Lung, and Blood Institute; and Thoracic Surgery Foundation for Research and Education Research Grant (GA). 


\section{References}

1. The Next Four Decades, The older Population in the United States: 2010 to 2050. U.S. Census Bureau; Washington DC: 2010.

2. Chaturvedi RK, Blaise M, Verdon J, et al. Cardiac surgery in octogenarians: long-term survival, functional status, living arrangements, and leisure activities. Ann Thorac Surg. Mar; 2010 89(3): 805-810. [PubMed: 20172133]

3. Akins CW, Daggett WM, Vlahakes GJ, et al. Cardiac operations in patients 80 years old and older. Ann Thorac Surg. Sep; 1997 64(3):606-614. discussion 614-605. [PubMed: 9307446]

4. Fruitman DS, MacDougall CE, Ross DB. Cardiac surgery in octogenarians: can elderly patients benefit? Quality of life after cardiac surgery. Ann Thorac Surg. Dec; 1999 68(6):2129-2135. [PubMed: 10616989]

5. Likosky DS, Dacey LJ, Baribeau YR, et al. Long-term survival of the very elderly undergoing coronary artery bypass grafting. Ann Thorac Surg. Apr; 2008 85(4):1233-1237. [PubMed: 18355501]

6. Likosky DS, Sorensen MJ, Dacey LJ, et al. Long-term survival of the very elderly undergoing aortic valve surgery. Circulation. Sep 15; 2009 120(11 Suppl):S127-133. [PubMed: 19752357]

7. Agarwal S, Banerjee S, Tuzcu EM, Kapadia SR. Influence of age on revascularization related costs of hospitalization among patients of stable coronary artery disease. Am J Cardiol. Jun 1; 2010 105(11):1549-1554. [PubMed: 20494660]

8. Pierorazio PM, Humphreys E, Walsh PC, Partin AW, Han M. Radical prostatectomy in older men: survival outcomes in septuagenarians and octogenarians. BJU Int. Mar 1.2010

9. Minatoya $\mathrm{K}$, Ogino $\mathrm{H}$, Matsuda $\mathrm{H}$, et al. Is conventional aortic arch surgery justifiable in octogenarians? J Thorac Cardiovasc Surg. Mar; 2010 139(3):641-645. [PubMed: 20176210]

10. Baskett R, Buth K, Ghali W, et al. Outcomes in octogenarians undergoing coronary artery bypass grafting. CMAJ. Apr 26; 2005 172(9):1183-1186. [PubMed: 15851711]

11. Aranki SF, Rizzo RJ, Couper GS, et al. Aortic valve replacement in the elderly. Effect of gender and coronary artery disease on operative mortality. Circulation. Nov; 1993 88(5 Pt 2):II17-23. [PubMed: 8222150]

12. Aranki SF, Shaw DP, Adams DH, et al. Predictors of atrial fibrillation after coronary artery surgery. Current trends and impact on hospital resources. Circulation. Aug 1; 1996 94(3):390-397. [PubMed: 8759081]

13. Smith KM, Lamy A, Arthur HM, Gafni A, Kent R. Outcomes and costs of coronary artery bypass grafting: comparison between octogenarians and septuagenarians at a tertiary care centre. CMAJ. Sep 18; 2001 165(6):759-764. [PubMed: 11584563]

14. Stamou SC, Dangas G, Dullum MK, et al. Beating heart surgery in octogenarians: perioperative outcome and comparison with younger age groups. Ann Thorac Surg. Apr; 2000 69(4):11401145. [PubMed: 10800808]

15. Sundt TM, Bailey MS, Moon MR, et al. Quality of life after aortic valve replacement at the age of >80 years. Circulation. Nov 7; 2000 102(19 Suppl 3):III70-74. [PubMed: 11082365]

16. de Vincentiis C, Kunkl AB, Trimarchi S, et al. Aortic valve replacement in octogenarians: is biologic valve the unique solution? Ann Thorac Surg. Apr; 2008 85(4):1296-1301. [PubMed: 18355513]

17. Dacey LJ, Likosky DS, Ryan TJ Jr, et al. Long-term survival after surgery versus percutaneous intervention in octogenarians with multivessel coronary disease. Ann Thorac Surg. Dec; 2007 84(6):1904-1911. discussion 1904-1911. [PubMed: 18036905] 
Table 1

Multivariable regression for Mortality

\begin{tabular}{|l|c|c|}
\hline Covariates & AOR $^{*}\left(\mathbf{9 5 \%} \mathbf{C I}^{\dagger}\right)$ & $\boldsymbol{P}$ \\
\hline Female Gender & $1.8(1.23-2.52)$ & $\mathbf{0 . 0 0 2}$ \\
\hline Non-Caucasian & $0.8(0.44-1.47)$ & 0.48 \\
\hline Age, year & $1.1(1.02-1.15)$ & $\mathbf{0 . 0 1}$ \\
\hline Dyslipidemia & $1.1(0.78-1.61)$ & 0.54 \\
\hline Peripheral Arterial Disease & $1.4(0.90-2.07)$ & 0.15 \\
\hline Stroke & $1.0(0.54-1.71)$ & 0.91 \\
\hline Diabetes & $1.0(0.71-1.51)$ & 0.84 \\
\hline Hypertension & $0.8(0.49-1.25)$ & 0.31 \\
\hline Infective Endocarditis & $0.8(0.10-6.84)$ & 0.85 \\
\hline Dialysis & $1.1(0.30-4.31)$ & 0.86 \\
\hline Smoker & $1.0(0.68-1.44)$ & 0.96 \\
\hline Previous CABG operation & $1.3(0.68-2.45)$ & 0.44 \\
\hline Previous Valve operation & $0.9(0.27-2.92)$ & 0.86 \\
\hline LVEF ${ }^{\S} \%$ & $1.0(0.97-1.00)$ & $\mathbf{0 . 0 1}$ \\
\hline NYHA ${ }^{\prime \prime}$ Class IV & $1.3(0.91-1.98)$ & 0.13 \\
\hline Preoperative Arrhythmia & $1.9(1.27-2.70)$ & $\mathbf{0 . 0 0 1}$ \\
\hline Aortic cross clamp, minutes & $0.9(0.97-0.99)$ & $<\mathbf{0 . 0 0 1}$ \\
\hline Cardiopulmonary bypass, minutes & $1.0(1.01-1.02)$ & $<\boldsymbol{0 . 0 0 1}$ \\
\hline Urgent & $1.7(1.13-2.50)$ & $\mathbf{0 . 0 1}$ \\
\hline Emergent & $6.4(3.30-12.56)$ & $<\boldsymbol{0 . 0 0 1}$ \\
\hline Isolated CABG ${ }^{\ddagger}$ & Reference & - \\
\hline Isolated Aortic Valve & $1.3(0.74-2.30)$ & 0.36 \\
\hline Isolated Mitral Valve & $1.6(0.61-4.19)$ & 0.33 \\
\hline Valve + CABG ${ }^{\ddagger}$ & $1.3(0.81-2.14)$ & 0.26 \\
\hline
\end{tabular}

Data included in analysis $90.2 \%$

Area under curve 0.7

* AOR, Adjusted Odds Ratio

${ }^{\dagger} \mathrm{CI}$, Confidence Interval

${ }^{*}$ CABG, Coronary Artery Bypass Graft

$\S_{\text {LVEF, Left Ventricular Ejection Fraction }}$

"NYHA, New York Heart Association Heart Failure 
Table 2

\section{Multivariable regression for Major Complications}

\begin{tabular}{|c|c|c|}
\hline Covariates & $\operatorname{AOR}^{*}\left(95 \% \mathbf{C I}^{\dagger}\right)$ & $P$ \\
\hline Female Gender & $1.2(1.01-1.52)$ & 0.05 \\
\hline Non-Caucasian & $1.4(1.05-1.91)$ & 0.02 \\
\hline Age, year & $1.0(1.01-1.09)$ & 0.01 \\
\hline Dyslipidemia & $1.1(0.86-1.32)$ & 0.56 \\
\hline Peripheral Arterial Disease & $1.1(0.84-1.38)$ & 0.58 \\
\hline Stroke & $1.2(0.87-1.65)$ & 0.28 \\
\hline Diabetes & $1.1(0.91-1.39)$ & 0.27 \\
\hline Hypertension & $0.7(0.57-0.96)$ & 0.02 \\
\hline Infective Endocarditis & $4.7(1.55-14.52)$ & 0.006 \\
\hline Dialysis & $1.4(0.61-3.19)$ & 0.44 \\
\hline Smoker & $0.8(0.67-1.03)$ & 0.09 \\
\hline Previous $\mathrm{CABG}^{+}$operation & $1.4(0.96-2.16)$ & 0.08 \\
\hline Previous Valve operation & $0.7(0.32-1.59)$ & 0.41 \\
\hline $\mathrm{LVEF}^{\S}, \%$ & $1.0(0.98-0.99)$ & $<0.001$ \\
\hline NYHA / Class IV & $1.4(1.10-1.74)$ & 0.006 \\
\hline Preoperative Arrhythmia & $1.4(1.09-1.76)$ & 0.007 \\
\hline Aortic cross clamp, minutes & $1.0(0.99-1.00)$ & 0.08 \\
\hline Cardiopulmonary bypass, minutes & $1.0(1.00-1.01)$ & $<0.001$ \\
\hline Urgent & $1.4(1.16-1.78)$ & 0.001 \\
\hline Emergent & $5.2(3.19-8.35)$ & $<0.001$ \\
\hline Isolated $\mathrm{CABG}^{+}$ & Reference & \\
\hline Isolated Aortic Valve & $0.8(0.58-1.15)$ & 0.26 \\
\hline Isolated Mitral Valve & $0.9(0.47-1.69)$ & 0.72 \\
\hline Valve $+\mathrm{CABG}^{+}$ & $1.2(0.89-1.57)$ & 0.26 \\
\hline
\end{tabular}

Data included in analysis $90.2 \%$

Area under curve 0.7

* AOR, Adjusted Odds Ratio

${ }^{\dagger} \mathrm{CI}$, Confidence Interval

${ }^{*}$ CABG, Coronary Artery Bypass Graft

$\S_{\text {LVEF, Left Ventricular Ejection Fraction }}$

"NYHA, New York Heart Association Heart Failure 
Table 3

Preoperative risk factors for patients undergoing cardiac operations

\begin{tabular}{|c|c|c|c|}
\hline Variable & Age $<80$ years $(N=41,756)$ & Age $\geq 80$ years $(N=3,975)$ & $P$ \\
\hline Age, years & $62.2(11.1)$ & $82.7(2.5)$ & $<0.001$ \\
\hline Male Gender & $29,240(70.0)$ & $2,310(58.1)$ & $<0.001$ \\
\hline Peripheral Vascular Disease & $5,819(13.9)$ & $732(18.4)$ & $<0.001$ \\
\hline Cerebrovascular disease & $5,639(13.5)$ & $924(23.2)$ & $<0.001$ \\
\hline Stroke & $2,849(6.8)$ & $380(9.6)$ & $<0.001$ \\
\hline Diabetes & $14,338(34.3)$ & $1,055(26.5)$ & $<0.001$ \\
\hline Dyslipidemia & $2,9459(70.6)$ & $2,610(65.7)$ & $<0.001$ \\
\hline Hypertension & $31,147(74.6)$ & $3,204(80.6)$ & $<0.001$ \\
\hline \multicolumn{4}{|l|}{ NYHA ${ }^{*}$, } \\
\hline Class I & $5,848(14.0)$ & $528(13.3)$ & \multirow{4}{*}{$<0.001$} \\
\hline Class II & $14,116(33.8)$ & $1,215(30.6)$ & \\
\hline Class III & $14,771(35.4)$ & $1,482(37.3)$ & \\
\hline Class IV & $7,021(16.8)$ & $750(18.9)$ & \\
\hline Heart Failure & 7,749 (18.6) & $1,099(27.6)$ & $<0.001$ \\
\hline Endocarditis & $775(1.9)$ & $24(0.6)$ & $<0.001$ \\
\hline Renal Failure & $2,337(5.6)$ & $247(6.2)$ & 0.10 \\
\hline Previous $\mathrm{CABG}^{\dagger}$ & $2,255(4.9)$ & $276(6.9)$ & $<0.001$ \\
\hline Previous Valve Surgery & $957(2.3)$ & $72(1.8)$ & 0.05 \\
\hline Heart Block & $286(0.7)$ & $75(1.9)$ & $<0.001$ \\
\hline Atrial Arrhythmia & $3,919(9.4)$ & $707(17.8)$ & $<0.001$ \\
\hline Ventricular Arrhythmia & $771(1.8)$ & $60(1.5)$ & 0.14 \\
\hline Ejection Fraction, \% & $50.4(12.8)$ & $50.5(12.4)$ & 0.35 \\
\hline
\end{tabular}

Data shown as $\mathrm{N}(\%)$ or Mean (SD), as appropriate

NYHA, New York Heart Association Heart Failure

${ }^{\dagger}$ CABG, Coronary Artery Bypass Graft 
Table 4

Procedure type and Operative features for patients undergoing cardiac operations

\begin{tabular}{|c|c|c|c|}
\hline Variable & Age $<80$ years $(N=41,756)$ & Age $\geq 80$ years $(N=3,975)$ & $P$ \\
\hline \multicolumn{4}{|l|}{ PROCEDURE TYPE } \\
\hline Any Valve & $8,682(20.8)$ & $1,330(33.5)$ & $<0.001$ \\
\hline Any $\mathrm{CABG}^{*}$ & $32,185(77.1)$ & $2,924(73.6)$ & $<0.001$ \\
\hline $\mathrm{AVR}^{\dagger}$ Only & $1,996(4.8)$ & $352(8.9)$ & $<0.001$ \\
\hline $\mathrm{AVR}^{\dagger}+\mathrm{CABG}^{*}$ & $1,697(4.1)$ & $506(12.7)$ & $<0.001$ \\
\hline $\mathrm{AVR}^{\dagger}+\mathrm{MVR}^{\dagger}$ & $169(0.4)$ & $20(0.5)$ & 0.37 \\
\hline CABG* Only & $26,707(64.0)$ & $1,992(50.1)$ & $<0.001$ \\
\hline $\operatorname{MVR}^{\ddagger}$ & $621(1.5)$ & $55(1.4)$ & 0.67 \\
\hline $\mathrm{MVR}^{\dagger}+\mathrm{CABG}^{*}$ & $388(0.9)$ & $71(1.8)$ & $<0.001$ \\
\hline $\mathrm{MV}^{\S}$ Repair & $776(1.9)$ & $26(0.7)$ & $<0.001$ \\
\hline $\mathrm{MV}^{\S}$ Repair $+\mathrm{CABG}^{*}$ & $737(1.8)$ & $77(1.9)$ & 0.42 \\
\hline Other procedure & $8084(19.4)$ & $796(20.0)$ & 0.35 \\
\hline \multicolumn{4}{|l|}{ OPERATIVE FEATURES } \\
\hline Elective & $22,011(52.7)$ & $2,080(52.3)$ & \multirow{3}{*}{0.89} \\
\hline Urgent & $17,882(42.8)$ & $1,722(43.3)$ & \\
\hline Emergent & $1,842(4.4)$ & $172(4.3)$ & \\
\hline Cardiopulmonary bypass, minutes & $112.9(53.1)$ & $117(54.1)$ & $<0.001$ \\
\hline Aortic cross clamp, minutes & $80.0(39.6)$ & $83.4(39.6)$ & $<0.001$ \\
\hline
\end{tabular}

Data shown as $\mathrm{N}(\%)$ or Mean (SD), as appropriate

* CABG, Coronary Artery Bypass Graft

${ }^{\dagger}$ AVR, Aortic Valve Replacement

†MVR, Mitral Valve Replacement

$\S_{\text {MV, Mitral Valve }}$ 
Table 5

Postoperative complications and Outcomes for patients undergoing cardiac operations

\begin{tabular}{|c|c|c|c|}
\hline Variable & Age $<80$ years $(N=41,756)$ & Age $\geq 80$ years $(N=3,975)$ & $P$ \\
\hline \multicolumn{4}{|l|}{ COMPLICATIONS } \\
\hline Sepsis & $571(1.4)$ & $62(1.6)$ & 0.32 \\
\hline Stroke & $663(1.6)$ & $102(2.6)$ & $<0.001$ \\
\hline Perioperative Myocardial Infarction & $108(0.3)$ & $15(0.4)$ & 0.20 \\
\hline Reoperation for Bleeding/Tamponade & $1,065(2.6)$ & $142(3.6)$ & $<0.001$ \\
\hline Atrial fibrillation & $6,517(15.6)$ & $1,013(25.5)$ & $<0.001$ \\
\hline Heart Block & $672(1.6)$ & $153(3.8)$ & $<0.001$ \\
\hline Cardiac Arrest & $663(1.6)$ & $107(2.7)$ & $<0.001$ \\
\hline Gastrointestinal Event & $1,035(2.5)$ & $153(3.8)$ & $<0.001$ \\
\hline Pneumonia & $1,534(3.7)$ & $204(5.1)$ & $<0.001$ \\
\hline Prolonged Ventilation & $4,768(11.4)$ & $634(15.9)$ & $<0.001$ \\
\hline Renal Failure & $1,908(4.6)$ & $319(8.0)$ & $<0.001$ \\
\hline Dialysis & $857(2.1)$ & $133(3.3)$ & $<0.001$ \\
\hline \multicolumn{4}{|l|}{ RESOURCE ULTILZATION } \\
\hline Preoperative Length of Stay, days & $3.9(1.4)$ & $2.8(6.9)$ & 0.65 \\
\hline Readmission <30 days from Surgery & $3,532(8.5)$ & $378(9.5)$ & 0.03 \\
\hline $\mathrm{ICU}^{*}$ Length of Stay, hours & $82.2(165.6)$ & $108.7(174.2)$ & $<0.001$ \\
\hline Hospital Length of Stay, days & $11.6(269.4)$ & $12.5(12.8)$ & 0.80 \\
\hline \multicolumn{4}{|l|}{ OUTCOMES } \\
\hline Major Complication & $3,502(8.4)$ & $524(13.2)$ & $<0.001$ \\
\hline Operative Mortality & $1,294(3.1)$ & $260(6.5)$ & $<0.001$ \\
\hline
\end{tabular}

Data shown as $\mathrm{N}(\%)$ or Mean (SD), as appropriate

* ICU, Intensive Care Unit 


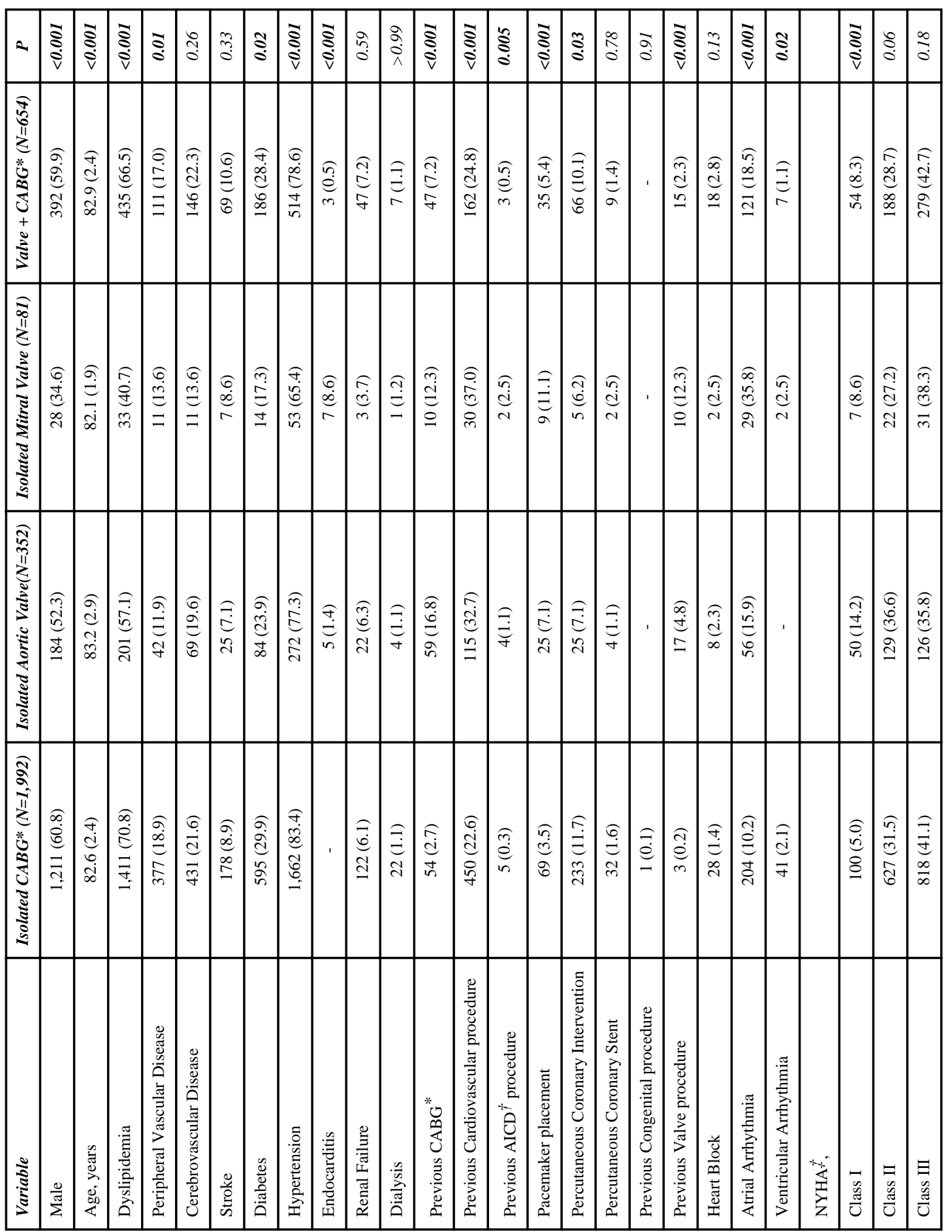




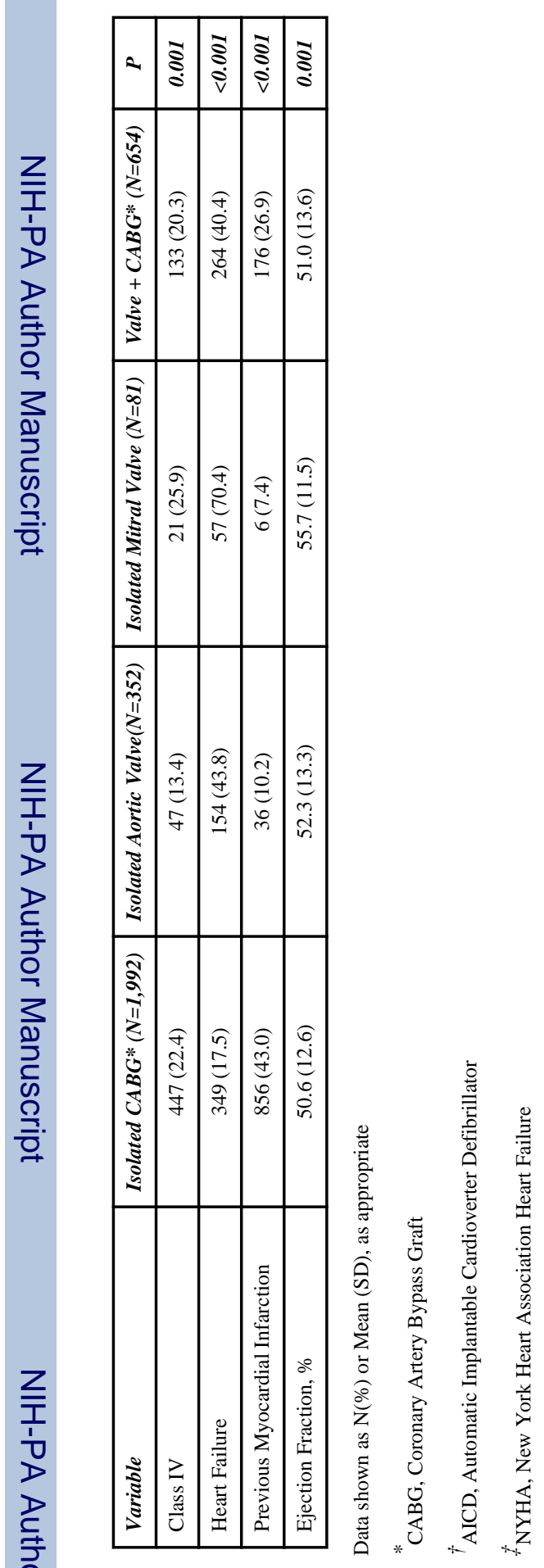




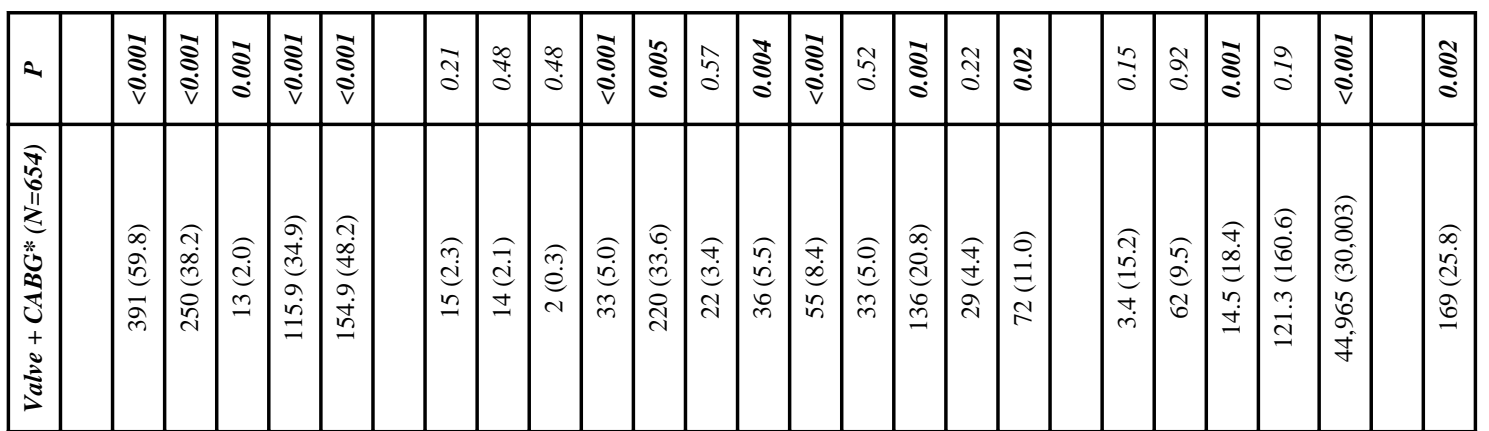

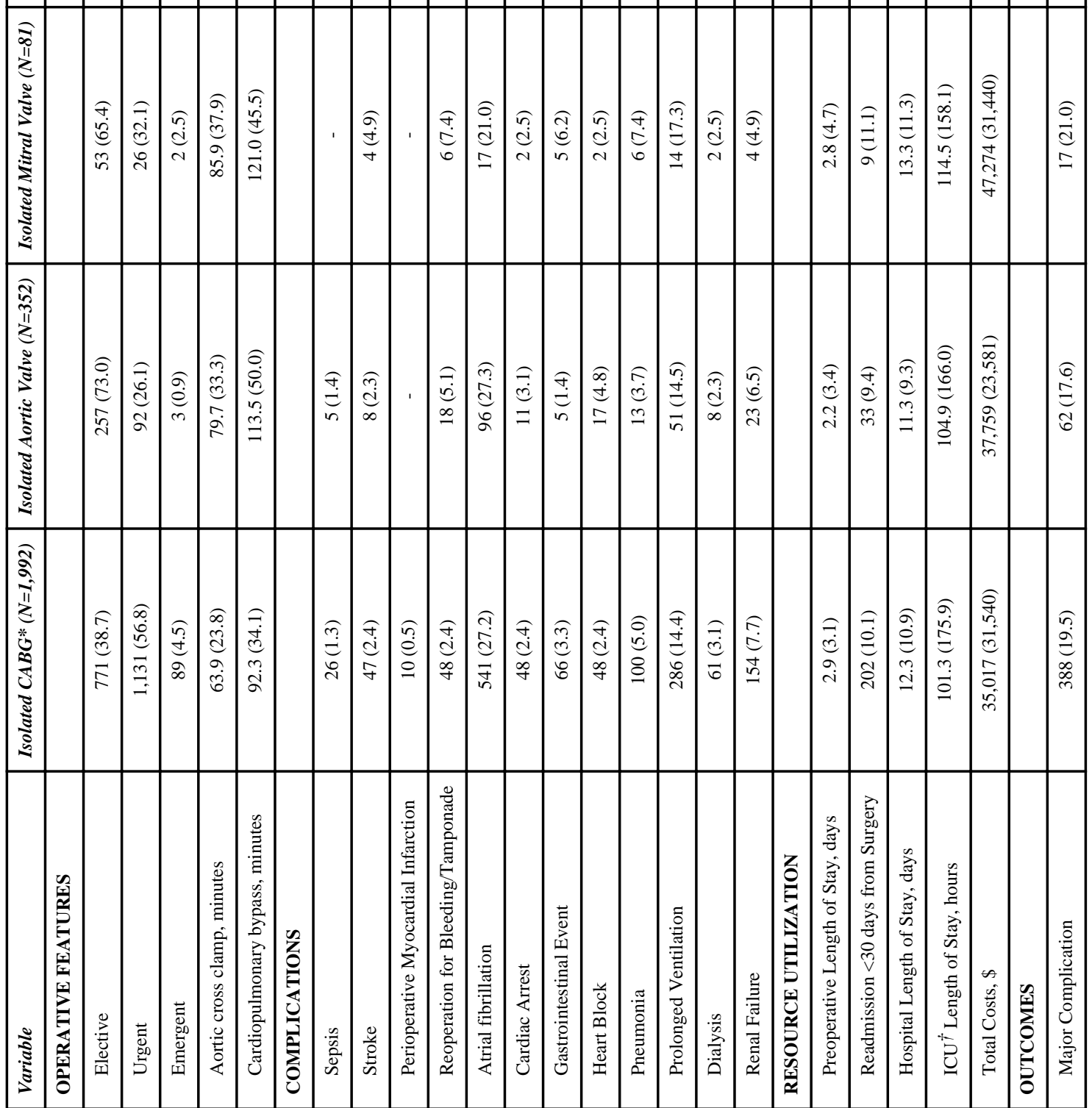




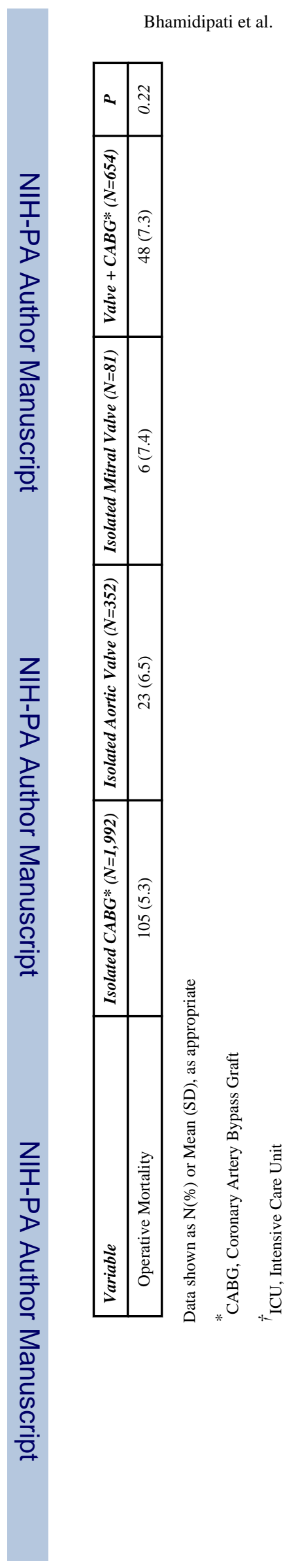

Page 15

Ann Thorac Surg. Author manuscript; available in PMC 2012 February 1. 